reaction may be only weakly positive; it remains positive in hydatidiform mole, but becomes negative when pregnancy is complicated by severe toxaemia. False positive reactions are sometimes seen in cases of over-function of the anterior lobe of the pituitary. It is difficult to say how reliable is the test. Kapeller-Adler claims almost $100 \%$ accuracy in cases of normal pregnancy, and only a $3 \%$ error in non-pregnant women. A few other workers have found it to be $99 \%$ accurate in cases of pregnancy, but record an error as high as $15 \%$ in non-pregnant women. It has been tried out in many laboratories in this country, and the fact that it has not come into general use and replaced biological tests rather indicates that it is not accurate enough to be of much practical value, or at least that reliable results depend to a large extent on the personal factor in the carrying out of the technique and in the interpretation of the colour reaction.

\section{Addison's Disease}

Q.-Has there been any recent advance in the treatment of Addison's disease? The present treatment consists in administration of extract of adrenal cortex and sodium chloride, but the question of gland implantation has been raised.

A.-Desoxycortone has proved a useful alternative to adrenal cortical extract and has two advantages: (1) $1 \mathrm{ml}$. is equivalent to $10 \mathrm{ml}$. of extract, and (2) tablets-for example, four of $100 \mathrm{mg}$. each - can be implanted in the subcutaneous fat of the abdomen and continue to act for some eight months. Recently in the U.S.A. Upjohns has produced a cortical extract from pigs which is said to be far more potent than the cortical extract usually obtained from cattle, in the proportion of one to five. Further, it is qualitatively richer in the glycogen-forming or carbohydrate-regulating hormone as distinct from the salt-andwater-regulating hormone, and this is of particular advantage in those patients with a tendency to hypoglycaemia. As to implantation of actual adrenal gland, this has been tried many times, and occasionally favourable reports are made. Broster recently reported a new technique in which a branch of the epigastric artery is implanted into the adrenal vein of the transplanted gland. However, in practice the method of adrenal transplanting has not come into popular use, and the probability is that it is too uncertain and hazardous.

\section{Beeswax in Oily Solutions of Penicillin}

Q.-Beeswax is incorporated in oily injections of penicillin to retard absorption. What is the fate of the injected beeswax and how does it act?

A.-The usefulness of incorporating $4.8 \%$ of beeswax in the arachis oil used as a vehicle for penicillin is amply attested by the work of Romansky and Rittman. The result is a very viscous medium undergoing slow dispersal; the contained penicillin is consequently slowly absorbed and exerts a prolonged action. The whole of the vehicle is ultimately disposed of by phagocytosis, and is said to have no injurious effect.

\section{Intertrochanteric Fracture of Femur}

Q.-Is an inch shortening and a right-angled coxa vara recognized as a good result following an intertrochanteric fracture of the femur?

A. -While the result described cannot be regarded as perfect, it would not necessarily be inconsistent with a satisfactory recovery of function. In an elderly patient such a result would be accepted by most surgeons if it was felt that a better anatomical reduction could be achieved only by operation. Though intertrochanteric fractures invariably unite, the union remains soft for five or six months in elderly patients, and it is during this late period that secondary deformation is likely to occur, resulting in coxa vara and shortening. The only way this can be prevented is by maintaining traction in bed for four or five months; or by subjecting the patient to an extensive operation to apply one of the several methods of internal fixation. As always in old people, it is a question of gaining sufficient function for their needs by a method which carries the least risk to life. In younger patients, however, it should always be possible to obtain a perfect anatomical and functional result by early complete reduction and maintenance of the reduction by internal or external splinting.

\section{Antiseptic Effect of Ether}

Q.-Ether applied to the skin and allowed to evaporate is not

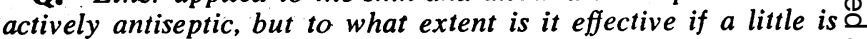
kept with a hypodermic syringe in a metal pocket-case?

A. - On the contrary, ether, although said to be less effective $\overrightarrow{\vec{F}}$ for the purpose than spirit, does kill extraneous bacteria on the $\vec{\sigma}$ skin. Neither can be depended on to sterilize a syringe. The most that ether can bo expected to do in the type of use $\frac{\overline{\bar{N}}}{\bar{D}}$ described is to sterilize the outside of the needle. For reference $\frac{\text { क }}{\vec{D}}$ to further information on the sterilization of syringes see last $\stackrel{\Phi}{\varrho}$ week's issue (p. 680).

\section{Toxicity of Phenobarbitone}

Q. -What daily dose of phenobarbitone is it safe to give for a prolonged period as a sedative? Does the drug accumulate, and if so what are the signs that this is taking place?

A.-The only guide to the'daily dose of phenobarbitone which it is safe to give as a sedative for a prolonged period is that the maximum pharmacopoeial dose is 2 gr. $(0.13 \mathrm{~g}$.). This is a dose for repeated use, and it remains for the doctor to. discover, for any particular patient, how often this dose can $\vec{\nabla}$ be repeated with safety. Patients vary a great deal in their ${ }^{\infty}$ susceptibility to all barbitone derivatives. "The variation has been determined for one derivative-namely, "sodium amytal "-and it was found that the most resistant patients required $Z$ four times as much as the most susceptible ones. It is likely that there are patients in whom 2 gr. of phenobarbitone daily $\frac{\Phi}{3}$ will produce some signs of accumulation, while others may tolerate $6 \mathrm{gr}$. $(0.4 \mathrm{~g}$.) or more daily. Phenobarbitone is excreted very slowly by the kidney and therefore accumulates. The $\vec{\omega}$ signs of accumulation are dullness and drowsiness;' there is $\$$ also a diminution in the depth of respiration.

\section{NOTES AND COMMENTS}

Tobacco and Poliomyelitis.-Dr. R. Monahan (Geneva) writes: 음 Referring to this subject in "Any Questions?" (Oct. 11, p. 598), 凤 this writer, in suggesting immunity for smokers, seems to have got $\overrightarrow{\overrightarrow{0}}$ hold of the wrong end of the stick. Tobacco smokers invariably develop the inflamed throat so favourable to infecting children. Nowadays children are brought up in a tobacco-drenched atmosphere, irritating their throats, rendering them more susceptible to the polio-? myeiitis virus. To-day the whole atmosphere of England is contaminated as the result of this filthy habit. It might be interesting to compare respective graphs showing the increase of smoking in the last 30 years and the greater incidence of poliomyelitis.

Loosening the Piston of a Syringe.-Dr. S. J. D. ESSER, Rustenburg, Transvaal, writes: The simplest way of loosening the piston of a syringe (Aug. 30, p. 358) is to dip the syringe in ice-water. Packing it with. ice is apt to crack the glass, as the cold 0 is distributed unevenly, but in every refrigerator there is a tray to catch the water when defrosting. We have to defrost every day $N$ to keep the refrigerator in good working order. The tray gets full $D$ of icy cold water in which the syringes are dipped and left for an hour or longer. We invariably find that the piston is then quite loose owing to the fact that metal contracts more than glass through $\mathbb{O}$ cold.

Addendum.-We should have indicated in our issue of Oct. $25 \%$ that the paper on "Shock in Obstetrics" by Prof. W. A. Scotto (p. 647) was read originally at the International Congress of Obstet- $\mathbb{\Phi}$ ricians and Gynaecologists held in Dublin from July 7-11 on the occasion of the Rotunda Bicentenary Celebrations.

All communications with regard to editorial business should be addressed to THE EDITOR, BRITISH MEDICAL JOURNAL, B.M.A. HOUSE, TAVISTOCK SQUARE, $Q$ LONDON, W.C.1. TELEPHONE: EUSTON 2111. TELEGRAMS: Aitiology, Westcent, London. ORIGINAL ARTICLES AND LETTERS forwarded for publication are understood to be offered to the Brtish Medical Journal alone unless the contrary be stated.

Authors desiring REPRINTS should communicate with the Publishing Manager, B.M.A. House, Tavistock Square, W.C.1, on receipt of proofs. Authorsoverseas should indicate on MSS. if reprints are required, as proofs are not sent abroad.

ADVERTISEMENTS should be addressed to the Advertisement Manager, B.M.A. House, Tavistock Square, London, W.C.1 (hours 9 a.m. to 5 p.m.) TELEPHONE: EUSTON 2111. TELEORAMS: Britmedads, Westcent, London. MEMBERS' SUBSCRIPTIONS should be sent to the SECRETARY of the Association. TELEPHONE: EUSTON 2111. TELEGRAMS: Medisecra, Westcent,

London.
B.M.A. Scotrish OFFICE: 7, Drumsheugh Gardens, Edinbureh. 